\title{
ALGUNAS CONSIDERACIONES ACERCA DE LA ESPADA DE GUADALAJARA. ¿UN EXCEPCIONAL DEPÓSITO DESARTICULADO DEL BRONCE MEDIO DE LA MESETA?
}

\author{
SOME THOUGHTS ON THE GUADALAJARA \\ SWORD. A DISMEMBERED HOARD \\ FROM THE MIDDLE BRONZE AGE ON THE \\ SPANISH MESETA?
}

DIRK BRANDHERM (*)

\section{RESUMEN}

En la bibliografía reciente, la tan conocida espada de Guadalajara, conservada hoy en el Museo Arqueológico Nacional, por la mayoría de los autores no sólo es tratada como pieza única sino también como hallazgo descontextualizado. No obstante, las primeras referencias publicadas sobre esta pieza, mientras todavía formaba parte de la colección Rodríguez Bauzá, parecen indicar que posiblemente en su origen pertenecía a un depósito que también incorporaba otras dos hojas de espada. Una de aquellas hojas probablemente se puede asociar a la chapa de oro suelta que hoy día se conserva junto con la espada restaurada ya en los años treinta. Durante la nueva restauración de este arma a fines de los años ochenta se hicieron visibles las huellas de dos enmangues distintos, demostrando así que el estado presente, con su suntuosa decoración de oro, corresponde a una modificación secundaria. Aunque en el caso de estas armas y sus enmangues cubiertos de oro se pudiera pensar en una influencia micénica, seguramente en el de los segundos por razones tecnológicas parece más probable un origen en la misma Meseta que en el Sureste, donde, en la cultura de ElArgar, más bien se estaría preparado para contar con la intrusión de elementos egeos.

(*) Becario postdoctoral. Departamento de Prehistoria y Arqueología. Universidad Autónoma de Madrid. Ciudad Universitaria de Cantoblanco. 28049 Madrid.

El artículo fue remitido en su versión final el 5-6-98.

\begin{abstract}
An exceptional gold-hilted sword, presumabiy from the province of Guadalajara, which today is kept in Madrid at the National Museum of Archaeology, has usually been treated as an isolated find. However, early references to this piece, when it was kept in the Rodríguez Bauzá collection, would seem to indicate that it may have formed part of a hoard together with two other swords, one of which apparently can be associated with fragments of a second hilt-cover of gold sheet, acquired originally with the complete sword. Furthermore, during re-restoration of the first sword, traces left on its surface from at least two different hilts, demonstrated that the current gold-covered design has to be considered a secondary modification. While some Mycenean influence in the design of these weapons and their ornaments cannot be ruled out, for technical reasons a production on the Meseta at least of the gold sheets seems more likely than in the Southeast, where the ElArgarculture is usually more readily associated with the diffusion of Aegean elements.
\end{abstract}

Palabras clave: Bronce Medio. Espada. Depósito. Meseta. Orfebrería.

Key words: Middlë Bronze Age. Sword. Hoard. Meseta. Goldwork. 


\section{INTRODUCCIÓN (1)}

Entre las espadas de la Edad del Bronce en la Península Ibérica destaca por su preciosa empuñadura de oro, riquísimamente decorada, una pieza probablemente hallada en tierras de Guadalajara, conservada en el Museo Arqueológico Nacional (MAN). El presente estudio pretende contextualizar este hallazgo sobre todo en lo que se refiere a las otras piezas que probablemente en un principio le acompañaron, y a las cuales, por presentar un aspecto menos extraordinario, usualmente no se ha prestado la misma atención. Al no tratarse de una pieza individual, sino de un depósito de varias piezas, el hallazgo de Guadalajara adquiere una nueva dimensión, que permite reevaluar el papel de los depósitos de armas del Bronce Medio en la Península Ibérica.

Otro aspecto importante, subrayado en el presente artículo y sólo conocido desde la renovada restauración de la pieza durante los años ochenta, es que presenta huellas de varias empuñaduras distintas, lo que permite concluir que la empuñadura de oro actual corresponde a una modificación secundaria. Ello a su vez indica una larga vida para algunas de estas armas suntuosas y recomienda cierta cautela en lo que se refiere a la valoración tipocronológica de los conjuntos cerrados respectivos.

\section{DESCUBRIMIENTO E INGRESO EN EL MUSEO ARQUEOLÓGICO NACIONAL}

A pesar de tratarse de una de las piezas más excepcionales que hoy día se encuentran en la colección de prehistoria del MAN, casi nada se sabe sobre la procedencia exacta o las circunstancias de hallazgo de la llamada "espada de Guadalajara" (Fig. 1, 1). Conocemos, eso sí, que en el año 1962 se compró a los herederos de D. Ramón Rodríguez Bauzá, junto con otra chapa de empuñadura de oro suelta (Fig. 1, 2 a), por Orden de la Dirección General de Bellas Artes de 1-III-1962 (Expediente del MAN 1962/9). Es este uno de los pocos datos exactos que conocemos de la historia de la pieza, conservada en la Colección Rodríguez Bauzá desde los

(1) Queremos expresar nuestro agradecimiento a la Dra. Dña. Carmen Cacho por facilitarnos la posibilidad de efectuar este estudio, como también a Concha Papí por su inestimable ayuda en la consulta de los expedientes correspondientes y finalmente a Ignacio Montero por su esfuerzo en mejorar nuestro deficiente castellano. años treinta, aunque solamente a partir de la década siguiente se publicaron las primeras referencias a esta pieza tan extraordinaria.

Cuando Ferrandis (1943: 161) en los inicios de los años cuarenta la cita por primera vez, sólo hace una muy breve mención a una espada de bronce con chapa de empuñadura de oro como pieza destacable, sin indicar su procedencia o las circunstancias de su hallazgo. Efectivamente, en el momento de su visita D. Ramón había muerto hacía ya varios años, y fue su viuda, $\mathrm{D}^{\mathrm{a}}$ María, quien se encargó de cuidar de la colección de su marido. Sólo a su muerte los herederos procedieron a vender la colección.

El único autor que nos ofrece datos sobre la historia de la pieza antes de entrar en la Colección Rodríguez Bauzá es Gómez-Moreno (1949: 341). Según sus palabras, D. Ramón la adquirió al anticuario D. Rafael García Palencia, quien la había comprado ya restaurada, siendo D. Ignacio Calvo, entonces jefe del gabinete numismático del MAN, el responsable de la restauración. También GómezMoreno, al referirse a la chapa de oro de la empuñadura, es el único autor que da una procedencia y fecha para su hallazgo (2).

Antes de Gómez-Moreno, Carriazo (1947: 792) aventura una procedencia asturiana, aunque admite que la procedencia y circunstancias del hallazgo son desconocidas. Aquí lo crucial es que, en sus reflexiones, Carriazo no sólo parece referirse a una espada, sino también a la segunda chapa de empuñadura, y a otras dos hojas de espadas de bronce, de las cuales dice que "acompañan" a la espada con empuñadura de oro (a la cual de aquí en adelante llamaremos hoja $\mathrm{n}^{\circ} 1$ y chapa de empuñadura $\mathrm{n}^{\circ} 1$ respectivamente) (3).

El hecho que Carriazo aparentemente concibiera las tres espadas "argáricas" de la Colección Rodríguez Bauzá como un único conjunto también podría explicar su sospecha acerca de su posible origen asturiano, porque el mejor paralelo de un conjun-

(2) "Ello es que, poco antes de 1930, aparecieron en tierra de Guadalajara ciertas piezas de oro, que con gran sigilo, a vistas de negocio comercial, fueron restauradas [...], resultando una espada de bronce, semejante a las de Atarfe y Linares, aunque menos larga, provista de empuñadura de oro, en chapas clavadas cuidadosamente sobre un alma de madera, desde luego moderna" (Gómez-Moreno, 1949: 341).

(3) "A esta sorprendente espada acompañan los restos de otra empuñadura semejante, reducida a la caña central, aplastada, de 10 centímetros, otra hoja de espada plana, argárica, de bronce, despuntada y rota antes de llegar a los clavos, con longitud de 52 centímetros, y otra hoja de daga o espada corta, de los mismos caracteres, de 35 centímetros de larga, que conserva uno de los tres clavos que afianzaban su empuñadura“" (Carriazo, 1947: 792). 
to de tales características efectivamente procede de la zona, más precisamente de la Cuevallusa de Ruesga en Cantabria, y a el Carriazo (1949: 793) se refiere en el siguiente párrafo.

La pertenencia de la hoja $\mathrm{n}^{\circ} 1$ y su respectiva chapa de empuñadura a un conjunto de tres espadas explicaría la presencia de la segunda chapa de oro (chapa de empuñadura $n^{\circ} 2$ ), que en casi todas las publicaciones desde la contribución de Carriazo a la Historia de España de Menéndez Pidal se viene mencionando como pieza hermana de la chapa de empuñadura de la espada $n^{\circ} 1$. Por su gran parecido como obras de orfebrería y por el carácter único de su decoración, ninguno de los autores cuestionó su pertenencia al mismo hallazgo. Gómez-Moreno (1949: 341), incluso, nos informa explicítamente que ambas aparecieron juntas.

\section{DISCUSIÓN HISTORIOGRÁFICA}

Curiosamente, a ningún investigador le pareció extraña la combinación de una espada completa con empuñadura de oro y otra empuñadura suelta, pese a que tal tipo de depósito carece de paralelo tanto durante el Bronce Medio, período al cual pertenecería desde un punto de vista tipológico la hoja $\mathrm{n}^{\circ} 1$, como durante épocas anteriores. Tampoco encajaría bien en los depósitos compuestos por fragmentos de armas y útiles del Bronce Final, en las cuales la inclusión de una espada entera sería infrecuente. Por el contrario durante el Bronce Medio, hallazgos como los de Cuevallusa y Villaviudas nos presentan la deposición conjunta de varias espadas completas (Leguina y Vidal, 1914: 55-56; Palol Salellas, 1969: 295-298; Rodríguez et alii, 1988: 219-223).

Sería entonces lógico suponer que la segunda chapa de empuñadura en el momento de su deposición iba junto con la correspondiente hoja. Efectivamente, entre las otras dos espadas mencionadas por Carriazo hay una hoja que encaja muy bien con la chapa $n^{\circ} 2$ (Fig. 1,2 b). Muy probablemente esta segunda hoja y la chapa $\mathrm{n}^{\circ} 2$ no se restauraron del mismo modo que la espada $n^{\circ} 1$ por el mal estado de conservación en que se encontraron: a la hoja de espada $n^{\circ} 2$ la falta gran parte de la placa del enmangue y también la chapa de empuñadura está muy dañada e incompleta. En su tratamiento de los paralelos de la espada $n^{\circ} 1$ a Almagro Gorbea (1972: nota 38 ) se le escapó la procedencia de la hoja $n^{\circ} 2$ de la Colección Rodríguez Bauzá. De lo contrario,

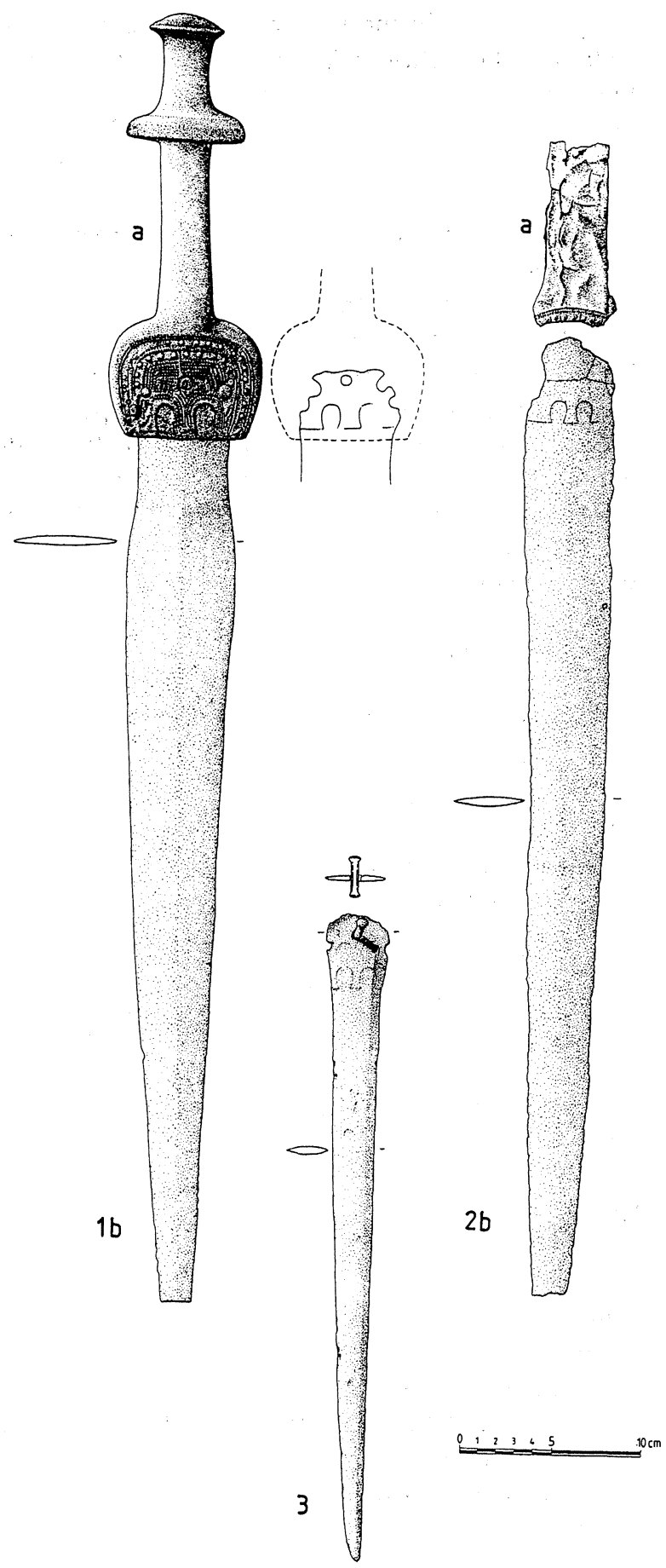

Fig. 1. Las tres espadas de la Colección Rodríguez Bauzá, hoy día conservadas en el Museo Arqueológico Nacional, originalmente con toda probabilidad formando un conjunto cerrado, procedente de la provincia de Guadalajara (dibujo G. Endlich).

probablemente ya hubiese sospechado una relación con la chapa de empuñadura $n^{\circ} 2$. 
Que la relación entre ambos elementos nunca fue tratada en la bibliografía asimismo encuentra parte de su razón en la mala conservación tanto de la hoja como de la chapa de empuñadura $n^{\circ} 2$, centrandose el interés científico siempre en la hoja $\mathrm{n}^{\circ} 1 \mathrm{y}$ su correspondiente chapa de empuñadura precisamente por su mejor conservación y la resultante restauración.

La desconexión entre ambos elementos aumentó con el procedimiento seguido en la adquisición de los materiales. En 1962 el MAN adquirió por compra la espada $\mathrm{n}^{\circ} 1$ completa junto a la chapa de oro $\mathrm{n}^{\circ} 2$, mientras que al mismo tiempo las hojas de espadas $n^{\circ} 2$ y 3 ingresaron en el museo en depósito como parte de un lote de la colección Rodríguez Bauzá compuesto por 17 piezas de distintas épocas y diversas procedencias. Este segundo lote sólo se compró dos años más tarde, por Orden Ministerial de 30-II-1964 (Expediente del MAN 1964/28). De este modo se perdió el carácter de conjunto que describiera Carriazo (4).

Su indicación de que desconocía las circunstancias del hallazgo de la espada $n^{\circ} 1$ no se debe entender necesariamente como contradictorio con la idea de que, ya en el momento de su descubrimiento, la pieza pertenecía a un conjunto de tres espadas. Lo que expresaría es que o Carriazo no estaba muy seguro del carácter de este "conjunto", y por eso prefirió una fórmula algo más ambigua, o bien era tan evidente para él que se trataba de un conjunto que, sin decirlo explícitamente, se refería también a las otras piezas cuando afirmaba que las "circunstancias de hallazgo se desconocen". Con todo, no se puede rechazar por completo la posibilidad que Carriazo, al utilizar el término "acompañan", sólo hiciera referencia al modo como las piezas se encontraban expuestas en la Colección Rodríguez Bauzá, sin pensar que originariamente formasen un conjunto. Pero, entonces, cuesta entender que no mencionase también otros dos puñales de bronce que se conservaban en la misma Colección y que ingresaron en el MAN junto con el resto de los materiales de la colección (Expediente del MAN 1964/28).

(4) El precio de 400.000 pesetas, al cual en 1962 se adquirieron la hoja $\mathrm{n}^{\circ} 1$ y las dos chapas de empuñadura (Expediente del MAN 1962/9), se debe considerar muy alto para la época, a no decir exagerado, y por la fecha bien puede haber influido sobre la decisión del MAN de no comprar la colección completa en este mismo momento. Así el resto de la colección, permaneciendo en el MAN ya en depósito durante dos años, se resolvió adquirir por compra en 1964 al precio relativamente moderado de 100.000 pesetas (Expediente del MAN 1964/28).
En todo caso, si se acepta que estamos tratando con un conjunto de tres espadas, dos de las cuales con empuñaduras chapeadas de oro, tal conjunto debe interpretarse como un depósito similar al de Cuevallusa (Leguina y Vidal, 1914: 55-56), aunque cronológicamente se situaría en un momento algo más tardío que este. $\mathrm{Si}$, por el contrario, rechazamos la idea de que las tres hojas forman parte del mismo depósito, lógicamente también tendríamos que rechazar la pertenencia de las dos chapas de oro, tan similares, al mismo conjunto, y atribuir a una casualidad la presencia simultánea de esas dos piezas excepcionales en la misma colección.

Quedaría una tercera posibilidad, y es que las chapas sí se hallaran juntas, pero ninguna de ellas relacionada con las hojas, y sólo la restauración posterior y la presentación común en la Colección Rodríguez Bauzá las conectará de una manera fortuita con unas espadas, que Carriazo percibía como acompañando a las chapas de empuñadura. Esta posibilidad fue discutida ya por Gómez-Moreno (1949: 341) para la hoja ${ }^{\circ} 1$. Sin embargo, Almagro Gorbea (1972: 57-58), el primero en dedicar un detenido estudio a la espada $\mathrm{n}^{\circ} 1$ y a las dos empuñaduras de oro, apoyado en radiografías de la pieza restaurada, llegó a la conclusión que muy probablemente la hoja $\mathrm{n}^{\circ} 1$ y la chapa de empuñadura $n^{\circ} 1$ habían constituido un conjunto ya desde la antigüedad. Sus dudas principalmente resultaron de la ausencia de remaches en la pieza una vez restaurada, pero, obviamente, tenemos que contar con la posibilidad que los remaches se perdieran en el momento del hallazgo o incluso que se quitaran en el curso de la primera restauración. Tampoco los daños que se pueden observar en el extremo proximal de la hoja impedirían que la empuñadura se sujetase por remaches, tanto más cuanto que, en su último estado, obviamente no se trataba de una arma para uso en combate, sino de una pieza suntuosa, destinada a representar el prestigio de su dueño.

Cuando en 1989 se desmontó la restauración antigua del mango para sustituir el soporte de madera por un nuevo soporte de resina, las huellas en la zona del enmangue indicaron que, efectivamente, la chapa de empuñadura $n^{\circ} 1$ había acompañado a la respectiva hoja desde la Edad del Bronce, pero además mostraron claramente que la hoja ${ }^{\circ} 1$ inicialmente tuvo otra empuñadura de forma algo distinta. Aquella primera empuñadura terminaba casi un centímetro más arriba que la actual y mostraba un escote en forma de doble herradura, mientras que 


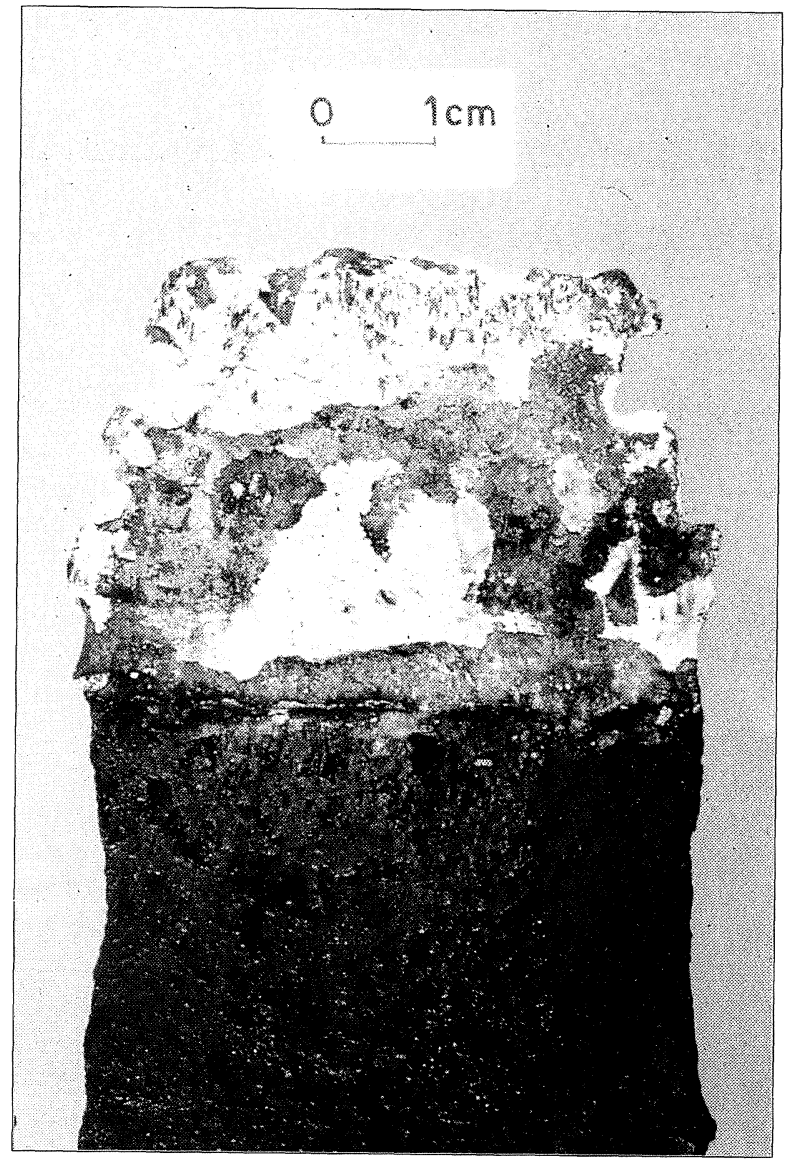

Lám. I. La espada n ${ }^{\circ} 1$ durante su restauración en 1990 , removida la empuñadura reconstruida; se observan muy bien las distintas huellas de las diferentes empuñaduras (Archivo Fotográfico. Museo Arqueológico Nacional).

en la chapa $\mathrm{n}^{\circ} 1$ tal forma sólo está presente como ornamento repujado. La chapa como tal termina en una línea recta, conservándose su huella también en la pátina de la hoja. Hoy día muestra una tercera huella muy débil, unos milímetros más abajo de esta segunda huella, también de forma aproximadamente recta (Lám. I). Aquella tercera huella al parecer tiene su origen en la restauración de los años treinta, cuando se eliminó la doblez perpendicular de las chapas laterales, alargandolas un poco hacia abajo (Almagro Gorbea, 1972: 56; Gago Blanco, 1990: 11).

Con respecto a la espada, tal y como se presenta en la actualidad, esta observación indica que cronológicamente la hoja pudiera ser algo más antigua que la chapa de empuñadura, lo que encaja muy bien con los respectivos paralelos tipológicos. La hoja de la espada $\mathrm{n}^{\circ} 1$ pertenece al grupo IIa de Almagro (tipo Moaña-Guadalajara), con una posición cronológica en pleno Bronce Medio (Almagro Gorbea, 1972: 69-71; 1976: fig. 10. 11). En cuanto a las chapas de oro $\mathrm{n}^{\circ} 1$ y 2 , encuentran sus mejores paralelos en dos piezas del depósito deAbía de la Obispalía, atribuible ya al Bronce Tardío o incluso al Bronce Final (Almagro Gorbea, 1974: 89).

Las espadas $\mathrm{n}^{\circ} 2$ y 3 se incluirían respectivamente en los grupos IIc (tipo Argar 824-Forcas) y IId (tipo Montejícar) según Almagro Gorbea (1972: 65; 1976: fig. 10. 11), de las cuales el primer subgrupo parece representar una tendencia algo más progresiva dentro de la evolución de las hojas de espada del Bronce Medio que el grupo IIa. Sin embargo tal tendencia tipocronológica no permite necesariamente atribuir una fecha más reciente a todos los representantes individuales de este subgrupo, ya que el subgrupo IId demuestra unos rasgos claramente más arcaicos dentro de la misma evolución. Por otra parte, precisamente los restos de deterioro en el extremo proximal de la hoja $\mathrm{n}^{\circ} 3$ y una secuencia de dos huellas en forma de doble herradura en su zona del enmangue señalan la existencia de dos empuñaduras consecutivas y nos hacen sospechar una vida larga para esta pieza.

Aceptando la idea de que muy probablemente se trata de un grupo de tres espadas depositadas en conjunto, el lugar de procedencia del depósito queda todavía como pregunta abierta. Carriazo (1947: 792), primer autor en tratar este asunto, afirma que la desconocía, mientras que Gómez-Moreno (1949: 341), al referirse a las chapas de la empuñadura, da como seguro que "aparecieron en tierra de Guadalajara". No sabemos dónde obtuvo esta información, pero los detalles que relata sobre la historia de las piezas antes de ingresar en la Colección Rodríguez Bauza claramente indican que disponía de alguna fuente de información a la cual ni Carriazo ni otro autor de la época tuvieron acceso.

En este contexto no se debe olvidar que, entre los años veinte y los años cincuenta, el mismo GómezMoreno era uno de los coleccionistas de armas prehistóricas más destacados del país, disponiendo de un conocimiento buenísimo del mercado de antigüedades. Aunque informaciones derivadas de este ámbito siempre merecen cierta cautela, particularmente en cuanto a la procedencia de los materiales, aquí una indicación tan general no da motivo a pensar en una falsificación, tanto menos cuanto que hay otros argumentos que hablan en favor de una procedencia de la zona. Particularmente las dos chapas 


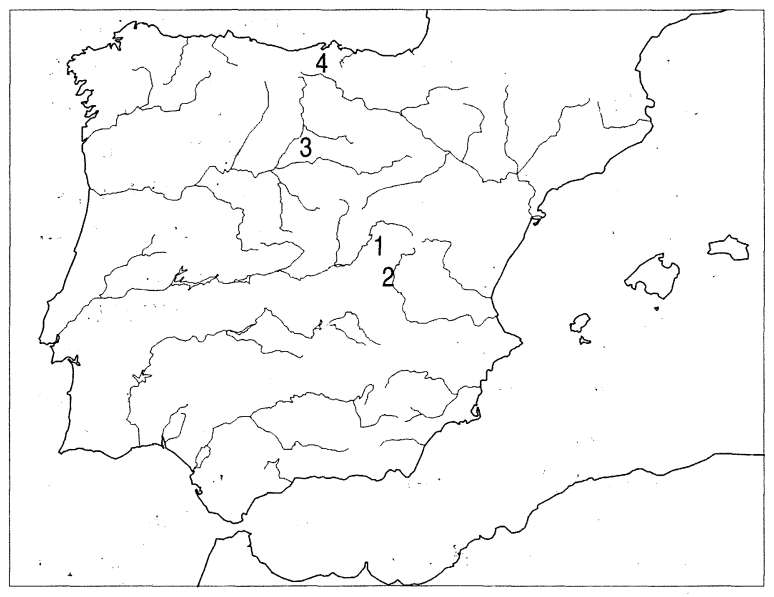

Fig. 2. Localización de los hallazgos mencionados en el texto. 1 = Guadalajara; 2 =Abía de la Obispalía; 3 =Villaviudas; $4=$ Cuevallusa.

de oro del depósito de Abía de Obispalía, mencionadas ya por Carriazo (1947: 792-793) como mejores paralelos de las chapas de empuñadura $\mathrm{n}^{\circ} 1 \mathrm{y}$ 2 , nos hacen pensar en un origen meseteño también para estas piezas.

Los mejores paralelos para las hojas $\mathrm{n}^{\mathrm{o}} 1$ y 2 asimismo se hallan en la Meseta, y aunque espadas de la misma filiación tipológica aparecen también en el ámbito argárico, su distribución principal se encuentra claramente en el centro y el norte de la Península Ibérica. Solamente el tipo de la hoja $\mathrm{n}^{\circ} 3$ tiene su origen indudable en el mediodía de la Península y hasta el momento no cuenta con paralelos en la Meseta (Almagro Gorbea, 1976: fig. 10; Brandherm, e.p.). Desde un punto de vista técnico las chapas de oro asimismo se deben considerar productos muy atípicos de la zona argárica, donde en la orfebrería predomina la fundición o bien la forja maciza, por tanto hay pocas probabilidades de que el conjunto tuviera allí su origen.

Sólo en el extremo septentrional del ámbito argárico se conocen trabajos comparables por su técnica en chapa de oro, quizá debido a la tradición de la orfebrería del mundo campaniforme, tan presente en la vecina Meseta durante el Bronce Antiguo (Brandherm, 1996: 56-57). Tampoco se puede excluir la posibilidad que las espadas con empuñaduras de oro del Egeo o del Mediterráneo oriental aquí sirvieran como modelos, ya que es precisamente por esa zona, la Vega Baja del Segura y la Huerta de Murcia, por donde la mayoría de las influencias foráneas de la época parece entrar en la Península Ibérica.

T. P., 55, n. $^{\circ} 2,1998$
Bien es verdad que no existe un parentesco tipológico inmediato entre las hojas $\mathrm{n}^{\circ} 1$ y 2 del depósito de Guadalajara y las armas suntuosas micénicas. El origen de su forma está mucho más relacionado con las espadas tipo Tréboul-SaintBrandan del oeste europeo (Almagro Gorbea, 1972: 61), así como últimamente con las hojas del complejo tipológicoApa-Hajdúsámson-Torupgårde de Centroeuropa (Hachmann, 1957: 90-111), que con formas del propio ámbito mediterráneo. No obstante, el pronunciado alargamiento de las hojas ibéricas durante el Bronce Medio quizá se debe a una influencia tipológica secundaria por parte de los estoques micénicos sobre estos prototipos occidentales.

Entre las espadas ibéricas sólo el tipo Montejícar, representado por la hoja $\mathrm{n}^{\circ} 3$ del conjunto de Guadalajara, quizá posea una relación tipológica algo más estrecha con los estoques micénicos, pero un origen peninsular de esta pieza también queda fuera de toda duda, así como la producción local de otras armas del Occidente europeo, que demuestran una clara inspiración en las armas suntuosas de Micenas (Schauer, 1984: 175-186).

Así, un origen meseteño de las piezas pertenecientes a este conjunto, en particular de las chapas de oro, parece el más probable, aunque no se puede excluir de modo absoluto una producción de cualquiera de las hojas en el propio Sureste peninsular (Fig. 2).

\section{DESCRIPCIÓN}

Hoja de espada $n^{\circ} 1$ (Fig. 1,1 b): presenta un ensanche muy ligero inmediatamente por debajo de la zona del enmangue; la misma cabeza del empalme está fuertemente dañada. De las cinco perforaciones para remaches dispuestas en forma de trapecio sólo la central se encuentra entera, las laterales por erosión de los bordes están incompletas. No se conserva ninguno de los remaches. También se presenta roto el extremo distal, que está retocado en la rotura. Los daños en ambos extremos parecen anteriores a la deposición de la pieza en el suelo; quizá incluso son anteriores al montaje de la chapa de empuñadu$\mathrm{ra}^{\circ} 1$. La sección de la hoja tiene forma fusiforme aplanada. En general la conservación de la superficie es buena, presentando en el anverso una pátina de color verde oliva oscuro, eliminada en el reverso. Sólo en la zona del enmangue aparecieron cloruros de cobre como consecuencia de la restaura- 
ción de la pieza durante los años treinta. No obstante, es precisamente en esta zona, donde se muestran las huellas de dos empuñaduras distintas, de las cuales la más antigua en su borde distal presenta forma de doble herradura. La más reciente, por el contrario, termina en una línea casi recta. Esta última huella aparentemente se puede asociar a la empuñadura originalmente cubierta con la chapa de oro $\mathrm{n}^{\circ} 1$, que también muestra un ornamento en forma de doble herradura, pero que en este caso sólo está rehundido y no recortado, como fue la empuñadura anterior. En cuanto al aspecto metalúrgico de la hoja $\mathrm{n}^{\circ} 1$ se refiere, un reciente análisis espectrométrico de fluorescencia de rayos $\mathrm{X}$ nos permite hablar de un cobre arsenicado (Rovira Llorens et alii, 1997: 215 [núm. análisis: PA7513A]). Eso claramente contradice al resultado de un análisis espectroquímico semicuantitativo efectuado en los inicios de los años setenta, que indicaba un notable porcentaje de estaño en la composición de la pieza (Almagro Gorbea, 1972: nota 5). Aunque la problemática de los análisis por energía dispersiva de rayos X sobre superficies limpias está bien conocida (Rovira Llorens et alii, 1997: 7; Ankner, 1998: 157161), en este caso nos inclinamos a prestar mayor confianza a la metodología más moderna. Longitud actual $52,5 \mathrm{~cm}$. (con empuñadura reconstruida 71,5 $\mathrm{cm}$.); anchura máx. $6,0 \mathrm{~cm}$. (con empuñadura 7,8 cm.); grosor máx. 0,45 cm. (núm. inv. 1962/9/1).

Hoja de espada ${ }^{\circ} 2$ (Fig. 1, 2 b): la cabeza del empalme está bastante destruida, y a pesar de la restauración parcial de la pieza parece imposible determinar con alguna seguridad la posición original de los remaches. Además el ligero ensanche de la hoja sólo se puede observar en un lado de la pieza debido a la fuerte corrosión en algunos tramos del borde. Falta el extremo distal. La sección de esa pieza se asemeja a la forma fusiforme de la hoja $\mathrm{n}^{\circ} 1$, en general con tendencia algo más romboidal, ligeramente aplanada en la zona del enmangue. También comparte con la pieza anterior su huella de empuñadura en forma de doble herradura, en este caso única, por lo que parece lícito deducir que siempre estuvo provista de una empuñadura semejante a la primera de la hoja $\mathrm{n}^{\circ} 1$. Longitud actual $51,7 \mathrm{~cm}$.; anchura actual máx. 4,9 cm.; grosor máx. $0,55 \mathrm{~cm}$. ( $(0,43 \mathrm{~cm}$. en la zona del enmangue); peso 494 gr. (núm. inv. 73/62/104).

Hoja de espada $n^{\circ} 3$ (Fig. 1, 3): aproximándose tipológicamente más a los llamados "esto- ques" (5) que a las espadas propiamente dichas, también dispone de dos huellas de empuñadura superpuestas, ambas en forma de doble herradura, de las cuales la primera sólo se conserva en parte. Como el extremo proximal se encuentra dañado y el martillado de los bordes laterales se extiende por la zona del enmangue, cabe suponer que la pieza en un principio era más larga, y que la primera huella quizá se asoció a una forma de empuñadura algo distinta, posiblemente con otro remache en posición proximal y escotaduras laterales correspondientes. Quizá incluso el remache conservado, de sección cuadrangular redondeada, no perteneciera originalmente al arma sino que sólo se montara con la segunda empuñadura. Según un análisis espectrométrico de fluorescencia de rayos $\mathrm{X}$ la pieza es de cobre arsenicado (Rovira Llorens et alii, 1997: 215 [núm. análisis: AA0898]). Longitud actual $35,2 \mathrm{~cm}$.; anchura actual máx. $0,36 \mathrm{~cm}$.; grosor máx. $0,46 \mathrm{~cm} .(0,33 \mathrm{~cm}$. en la zona del enmangue; longitud del remache $2,20 \mathrm{~cm}$; grosor del remache $0,40 \mathrm{~cm}$. (núm. inv. 73/62/107).

Chapa de empuñadura $\mathrm{n}^{\circ} 1$ (Fig. 1,1 a): está compuesta originalmente por cinco láminas de oro, rotas hoy día en seis fragmentos principales y tres menores. Dos láminas trapezoidales totalmente decoradas cubriendo la mayor parte del anverso y del reverso del enmangue enlazan con el cilindro de la empuñadura misma y con sus "asas" laterales que, a su vez, cubren los flancos de la zona del enmangue. El pomo está revestido por otras dos láminas lisas y parece posible que, en un principio, en su base hubiera otra lámina de oro, en forma de disco circular, hoy perdida (Pingel, 1992: 248-249, fig. 59). Tanto Hartmann (1982: 86 [núm. análisis: Au 2012, Au 2014]. 92 [núm. análisis: Au 2013]) como Rovira Llorens et alii (1997, 215 [núm. análisis: PA7513B]. 216 [núm. análisis: PA7513C]) publicaron análisis metalúrgicos de las distintas láminas. La decoración de las dos láminas de anverso y reverso se compone de un ornamento rehundido en forma de doble herradura en su borde inferior y simples líneas de puntos a punzón rellenando casi todo el resto de su superficie, entre las cuales hay, próxima al borde superior de la lámina, una sola línea de bollitos repujados algo mayores. Los huecos entre las zonas puntilladas indican la posición

(5) Para la distinción entre los "estoques" y las espadas sensu stricto nos basamos en el criterio técnico según el cuál los primeros tienen hojas no aptas como arma cortante, sino pensadas exclusivamente para la estocada (Gordon, 1953: 67). 
de los cinco remaches. El borde inferior de la lámina de la empuñadura con las dos solapas también presenta decoración, compuesta por otra línea de bollitos repujados y dos líneas más de puntos a punzón, dejando liso el resto de la pieza. En relación a la hoja de bronce, hoy día asociada a esa chapa de empuñadura parece importante insistir en que el ornamento de doble herradura no está recortado sino rehundido, y que por eso la primera huella de empuñadura en la hoja, aunque efectivamente presenta forma de doble herradura, no se corresponde con esa chapa. Más bien por su posición sobre la hoja, a su vez asegurada por la localización de los remaches, la chapa ${ }^{\circ} 1$ sin lugar a dudas causó la huella recta algo más abajo de la huella recortada, relegando esa última a un momento anterior y a una empuñadura de forma distinta. Longitud $22,2 \mathrm{~cm}$.; anchura máx. $8,6 \mathrm{~cm}$.; grosor máx. $1,9 \mathrm{~cm}$.; diámetro del pomo $6,5 \mathrm{~cm}$.

Chapa de empuñadura ${ }^{\circ} 2$ (Fig. 1, 2 a): se conserva una sola lámina de oro, prevista para cubrir la parte de la empuñadura propiamente dicha y el borde superior del enmangue. Es muy semejante a la lámina central de la chapa de empuñadura $\mathrm{n}^{\circ} 1$. Actualmente está doblada y rota en varios puntos de su superficie (análisis metalúrgico en Hartmann, 1982: 88 [núm. análisis: Au 2011]). En su borde inferior presenta una decoración compuesta por una línea de pequeños cuadrados repujados, cada uno con un punto a punzón central, y por dos líneas de simples puntos a punzón. Longitud actual $10,0 \mathrm{~cm}$.; anchura actual max. 4,4 cm. (núm. inv. 1962/9/2).

\section{BIBLIOGRAFÍA}

Almagro Gorbea, M. (1972): "La espada de Guadalajara y sus paralelos peninsulares". Trabajos de Prehistoria, 29: $55-82$.

- (1974): "Orfebrería del Bronce Final en la Península Ibérica". Trabajos de Prehistoria, 31: 39-100.

- (1976): "La espada de Entrambasaguas: Aportación a la secuencia de las espadas del bronce en el norte de la Península Ibérica". En XL Aniversario del Centro de Estudios Montañeses, III. Diputación Provincial. Santander: 453-477.

ANKNER, D. (1998): "Korrosion von Kupferlegierungen im
Boden und ihre Bewertung".Archäologisches Korrespondenzblatt, 28 (1): 151-161.

BrandHERM, D. (1996): "Zur Nordprovinz der El ArgarKultur". Madrider Mitteilungen, 37: 37-59.

- (e.p.): Die Dolche und Stabdolche der Iberischen Halbinsel, I. Prähistorische Bronzefunde, VI. Franz Steiner Verlag. Stuttgart.

Carriazo, J. de M. (1947): "La Edad del Bronce”. En R. Menéndez Pidal (ed.): Historia de España, I. Espasa Calpe. Madrid: 753-852.

FERRANDIS, J. (1943): "Visita a la Colección RodríguezBauzá". Boletín de la Sociedad Española de Excursiones, 47: 157-162.

Gago Blanco, F. (1990): "La espada de Guadalajara - Restauración”. Revista de Arqueología, 106: 8-14.

Gómez-Moreno, M. (1949): "Sobre lo argárico granadino". En Misceláneas, Historia-Arte-Arqueología, primera serie: La antigüedad. Instituto Diego Velazquez. Madrid: 337-342.

Gordon, D.H. (1953): "Swords, Rapiers, and Horse Riders". Antiquity, 27: 67-78.

Hachmann, R. (1957): Die frühe Bronzezeit im westlichen Ostseegebiet und ihre mittel- und südosteuropäischen Beziehungen: Chronologische Untersuchungen. Beihefte zumAtlas der Urgeschichte, 6. Flemmings Verlag - Kartographisches Institut. Hamburg.

Hartmann, A. (1982): Prähistorische Goldfunde aus Europa, II. Studien zu den Anfängen der Metallurgie, 5. Gebr. Mann Verlag. Berlin.

LEGUINA Y VIDAL, E. (1914): "La espada española". En Discursos leidos ante de la RealAcademia de la Historia. Real Academia de la Historia. Madrid: 55-56.

PAlOl SAlEllas, P. (1969): "Una espada de bronce hallada en Villaviudas, provincia de Palencia". Boletín del Seminario de Estudios de Arte y Arqueología, 34/35: 295-298.

Pingel, V. (1992): Die vorgeschichtlichen Goldfunde der Iberischen Halbinsel. Madrider Forschungen, 17. Verlag Walter der Gruyter. Berlin-New York.

Rodríguez, J.A.; RoJo Guerra, M. y Fernández, J.M. ${ }^{\text {a }}$ (1988): "Una nueva espada del bronce medio hallada en Villaviudas (Palencia)". Boletín del Seminario de Estudios de Arte y Arqueología, 54: 219-223.

Rovira Llorens, S.; Montero Ruiz, I. y Consuegra RodríGUEZ, S. (1997): Las primeras etapas metalúrgicas en la Península Ibérica, I. Análisis de materiales. Instituto Universitario Ortega y Gasset. Madrid.

Schauer, P. (1984): "Spuren minoisch-mykenischen und orientalischen Einflusses im atlantischen Westeuropa". Jahrbuch des Römisch-Germanischen Zentralmuseums Mainz, 31: 137-186.

T. P., 55, n. ${ }^{\circ} 2,1998$ 